\title{
ENTREVISTA
}

\section{Brasil é parceiro na alfabetização de jovens e adultos em São Tomé e Príncipe}

Ana Cláudia MENEZES

especial para a revista Acolhendo a Alfabetização nos Países de Língua

Portuguesa

Alfabetização Solidária leva experiência e compartilha conhecimentos com o país africano

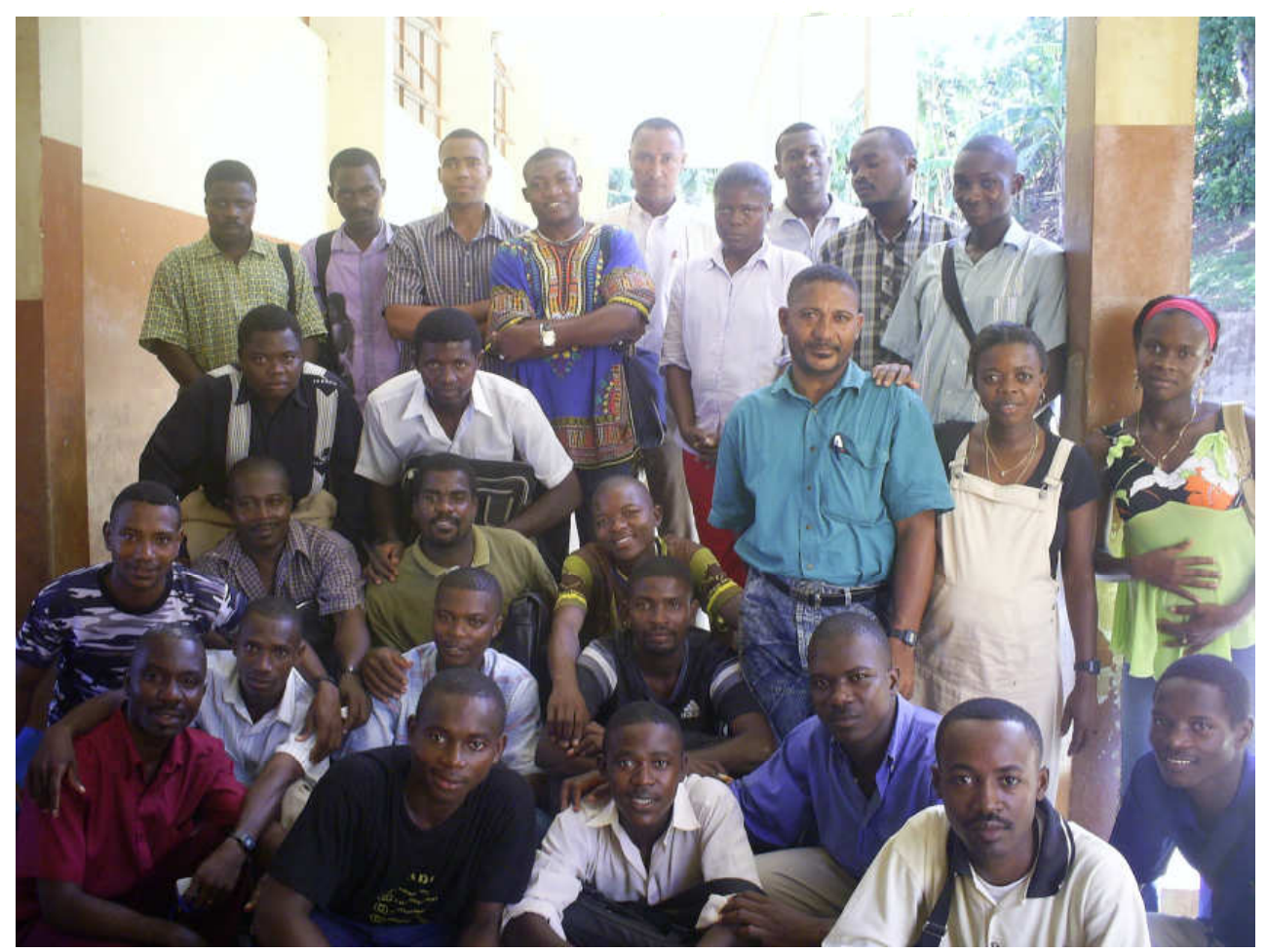

Foto 1 - Educadores de São Tomé e Príncipe participantes do Projeto Alfabetização Solidária, com o Brasil. 
Em abril de 2006, um grupo de quatro educadoras brasileiras chegou a São Tomé e Príncipe como integrantes do acordo de cooperação entre os governos dos dois países, com o objetivo de dar continuidade ao Projeto de Cooperação Técnica Alfabetização Solidária. Desde 2002, o Projeto Alfabetização Solidária em STP vem contribuindo na alfabetização de jovens e adultos na nação africana. Menor país do continente e com 193 mil habitantes, São Tomé e Príncipe é formado por oito ilhas, localizadas no Oceano Atlântico, a 250 quilômetros da costa oeste africana.

Participam da missão Ednéia Gonçalves, assessora técnica da Alfabetização Solidária, Francisca Maciel, professora da Faculdade de Educação da Universidade Federal de Minas Gerais (UFMG), Ana Lúcia Silva Souza, formadora do Programa de Educação de Jovens e Adultos (EJA) da ONG Ação Educativa, e Lorita Maria de Oliveira, educadora e professora da Universidade de Passo Fundo (UPF). A proximidade cultural entre os dois países ajudou, em muito, $\mathrm{o}$ andamento do projeto, assinado em 2001 e com atuação em outros países africanos de língua portuguesa, como Cabo Verde e Moçambique, e também em Timor Leste e Guatemala.

Ednéia e Ana Lúcia observam que, apesar das diferenças, Brasil e São Tomé e Príncipe têm diversas características em comum. "Em geral, alimentamos uma idéia um pouco mítica em relação à África. Não sabemos muito sobre o continente. O trabalho é uma excelente oportunidade para também aprender", explica Ednéia. "Como educadoras, nossa principal preocupação é saber quais são as necessidades de usos das línguas no cotidiano e compreender a importância de cada uma delas na vida das pessoas", comenta Ana Lúcia.

Acoalfaplp: São Tomé e Príncipe têm cinco línguas, como o português, idioma oficial, e o crioulo. Em qual língua serão alfabetizadas as pessoas envolvidas no projeto Alfabetização Solidária? 
Ednéia Gonçalves: A Alfabetização Solidária baseia sua atuação internacional no respeito à diversidade histórica, lingüística e sócio-cultural dos países nos quais atua. Identificamos em cada local a diversidade lingüística e status da língua portuguesa (oficial, materna, segunda língua), visando construir propostas educacionais que integrem a preservação da diversidade das línguas de comunicação e o acesso ao idioma oficial. Trabalhamos com as equipes locais e a ação educativa é desencadeada por alfabetizadores que dominam a língua materna e o português (língua oficial). Indicamos a língua materna como matriz da ação educativa e, o português, como língua de integração nacional.

Acoalfaplp: Como serão elaborados os materiais didáticos para os professores e alunos em São Tomé e Príncipe?

Ana Lúcia Silva e Souza: É importante ressaltar que o material didático terá a história e a cultura de São Tomé e Príncipe como fío que costura todo o processo. Cabe à Alfabetização Solidária oferecer apoio técnico para que as equipes locais pesquisem e desenvolvam materiais didáticos contextualizados com a realidade local.

Acoalfaplp: Quais são os próximos passos do projeto? Vocês retornarão ao país?

Ednéia: O Projeto Alfabetização Solidária em STP encontra-se em sua terceira fase. Além da capacitação continuada de alfabetizadores, desenvolvemos, nesta fase, apoio técnico para a realização de concurso de redação e capacitação específica da equipe técnica local, com o objetivo de atualizar os procedimentos de acompanhamento, formação, avaliação e registro de processos. Além disso, orientamos a estruturação do ensino recorrente (pós-alfabetização). O trabalho continua e os passos seguintes 
serão sempre definidos a partir da demanda formativa local. De acordo com os roteiros, com as reflexões e questionamentos, colocamo-nos para responder ao que o país solicita.

Acoalfaplp: Quais são os frutos do projeto, a curto, médio e longo prazo para a população de São Tomé e Príncipe?

Ednéia: Atualmente o país conta com 100 salas de aula espalhadas pelas localidades de Lembá, Cauê, Cantagalo, Mezóchi, Neves, Lobata, Guadalupe, Trindade, Água Grande e Príncipe. A partir dos resultados desta ação, o país implantou salas de ensino recorrentes (pós-alfabetização), estruturando, desta forma, um projeto denso de educação de jovens e adultos. Em médio e longo prazo, é possível aumentar o número de raparigas nas escolas - uma das preocupações é a educação das mulheres, um conjunto maior de pessoas que possam buscar formas de continuar os estudos, a valorização da cultura local, entre outros aspectos. Desta forma, podemos falar em possibilidades em vislumbrar dias mais prósperos para um lugar tão maravilhoso como é São Tomé e Príncipe.

Acoalfaplp: E o que mais se pode dizer sobre São Tomé e Príncipe?

Ana Lúcia: Ainda há muito o que se fazer neste país que apenas em 1975 conheceu a sua independência. Também há muito o que se conhecer. Por ora, registramos a beleza do verde que convive muito de perto com os baixos índices de desenvolvimento. Vive-se do pequeno comércio, da agricultura e quase que apenas disso. São Tomé é, quase que literalmente, a cara de uma parte do Brasil. Aliás, Brasil dá nome à praia e a uma significativa festa popular. As pessoas sabem muito do Brasil até porque assistem, entre outros, aos programas brasileiros. Ao andarmos pelas ruas parece que lá encontramos nossas bisavós, nossas avós, primos, tão grande é 
a semelhança dos traços físicos e culturais. As roupas, raramente trajes tradicionais, são coloridas, misturando o que se ganha dos projetos de ajuda internacional, o que se compra nas lojas da cidade e o que se amarra na cabeça e nas cinturas das mulheres que, de manhã à noite, carregam coisas na cabeça. Muito cedo, a cidade acorda e começa a grande circulação de pessoas pelas ruas. E muito tarde, as vilas dormem. As pessoas costumam ficar em frente às suas casas, nas ruas de pouca iluminação conversando, de pé ou acocoradas. Por lá ainda se contam histórias. Nada de cinema e teatro. São as festas que fazem a alegria das pessoas. Comem-se comidas saborosas à base de bananas fantásticas, matabala (uma espécie de mandioca) e frutapão, e trabalha-se muito para que dias melhores cheguem logo.

\section{Entrevistadora}

Ana Cláudia Menezes

Jornalista formada pela Universidade Federal de Santa Catarina (MTb 00530 SC) e mestranda em "Media, Conflict and Peace Studies" na University for Peace (San José, Costa Rica). Cobriu, para a Agência Carta Maior, o $5^{\circ}$ Fórum Social Mundial e o $1^{\circ}$ Fórum Social das Migrações, em 2005, em Porto Alegre. É autora do livro Memórias de um Patrimônio Edifícios Históricos do Badesc, publicado em 2001 com o patrocínio do governo do Estado de Santa Catarina.

anamenezes2002@hotmail.com

\section{Entrevistadas}

\section{Ana Lúcia Silva Souza}

Doutoranda em Lingüística Aplicada pelo Instituto de Estudos da Linguagem (IEL), da Universidade Estadual de Campinas (Unicamp). Mestre em Ciências Sociais pela Pontifícia Universidade Católica (PUC São Paulo). Desenvolve pesquisa sobre Práticas de Letramento no Movimento Hip Hop. Professora universitária na área de Sociologia da Educação. Assessora projetos sobre práticas de leitura e dinamização de acervo de literatura. 


\section{Ednéia Gonçalves}

Socióloga, 43 anos. Desde 1982 atua na gestão e formação de docentes e gestores educacionais em diferentes organizações não governamentais brasileiras. Em 2005, assumiu a Assessoria Técnica da Alfabetização Solidária coordenando, entre outras ações, o levantamento das demandas formativas de diferentes países envolvidos na Cooperação Técnica Internacional, assim como a elaboração de conteúdos e a coordenação de equipe de docentes envolvidos nas missões de formação de gestores e alfabetizadores de São Tomé e Príncipe, Cabo Verde e Moçambique na área de Educação de Jovens e Adultos.

\section{Como citar este artigo:}

MENEZES, Ana Cláudia. Brasil é parceiro na alfabetização de jovens e adultos em São Tomé e Príncipe. Entrevista in Revista ACOALFAplp: Acolhendo a Alfabetização nos Países de Língua portuguesa, São Paulo, ano 2, n. 3, 2007. Disponível em: <http://www.mocambras.org> e ou <http://www.acoalfaplp.org>. Publicado em: setembro 2007. 